\title{
Política e jurisdição: alterações recentes nos modelos constitucionais inglês, belga e francês*
}

\section{Politics and adjudication: recent changes on british, belgian and french constitutional systems}

Ana Lucia Pretto Pereira ${ }^{1}$

Recebido em: 09/08/2013.

Aprovado em: 13/05/2015.

1 Mestre em Direito Público pela Universidade Federal do Paraná - UFPR (2009). Em 2009, foi professora convidada do Programa de Pós-graduação (Especialização) das Faculdades do Brasil - UniBrasil, em Curitiba. Entre 2008 e 2011, trabalhou como assistente e coordenadora de pesquisas do Prof. Dr. Titutalr Clèmerson Merlin Clève, da UFPR. Em 2012, fez seu doutorado sanduíche na Harvard Law School, como bolsista da CAPES. Atualmente, está concluindo seu Doutorado também em Direito Público na UFPR. É bolsista do CNPq. Recentemente, publicou Political activity of Brazilian adjudication: some dimensions, nos Anais do 25th IVR World Congress of Philosophy of Law - Law, Science and Technology (Frankfurt, Alemanha), e tem o $\neg \neg \neg I l$ valore del precedente giurisdizionale nel sistema giuridico brasiliano no prelo para publicação em obra coletiva organizada por Antonio D’Aloia e Luca Mezzetti, pela Filodiritto Editora.

\section{Resumo}

O presente texto ilustra o que se reconhece como atividade política da jurisdição com alterações recentes operadas no campo do controle de constitucionalidade em três ordenamentos jurídicos diferentes. Inicialmente, apontam-se algumas noções do político e qual a sua dimensão no campo da jurisdição constitucional. Em seguida, apresentam-se mudanças em modelos de controle de constitucionalidade estrangeiros que parecem evidenciar que a jurisdição tem assumido papel de destaque na condução de assuntos de interesse público (em particular, através do reforço de sua competência para o controle da constitucionalidade). A relação entre a atividade política e os ordenamentos estrangeiros é feita por se compreender que tais mudanças refletem algo novo e significativo que vem ocorrendo no terreno da jurisdição constitucional, e que não é exclusivo do cenário político-jurídico brasileiro.

Palavras-chave: Jurisdição constitucional. Política. Direito. Controle de constitucionalidade.

\begin{abstract}
This article exemplifies what is here understood as a political activity of Judiciary with recent changes on three different legal systems of judicial review around the world. At first, some notions of the political and its dimension on constitutional adjudication are presented. Next, changes on the the judicial review system of three foreign experiences are shown, in order to suggest that the judiciary has assumed a central role regarding decision-making on political issues (in particular, by strenghtening its jurisdiction on judicial review). The relationship between the political activity and the foreign experiences is done for these changes seems to represent something relevant that has been happening on adjudication, which is not exclusive of the Brazilian legal and political scenario.
\end{abstract}

Keywords: Constitutional adjudication. Politics. Law. Judicial review. 


\section{Atividade política da jurisdição: apontamentos}

Os desenvolvimentos teóricos contemporâneos em matéria de direitos fundamentais, jurisdição constitucional e hermenêutica jurídica podem fazer deduzir que atuar a jurisdição a partir de critérios políticos é atividade cujos precedentes coincidem com o presente momento do constitucionalismo. No entanto, se uma das premissas do constitucionalismo contemporâneo é a atividade criativa da jurisdição, porque consciente das limitações inerentes a uma atitude hermenêutica meramente subsuntiva, esta premissa já era encontrável no próprio pensamento positivista que lhe precedeu. É o que se colhe, por exemplo, da tese de Kelsen acerca da interpretação jurídica.

Atribui-se a Hans Kelsen a mais apurada formulação teórica de reconhecimento de dignidade científica ao direito. Superada a "babel metodológica"2 do sociologismo eclético, o legalismo oitocentista cobra preocupação com um tratamento científico do direito, justamente para que fosse operado com rigor, coerência e previsibilidade. Sob o positivismo kelseniano, no direito teria sido identificado um objeto e, para o conhecimento desse objeto, um método específico. Para Kelsen, esse objeto seria a norma jurídica, ao passo que o método a ser aplicado pelo operador do direito deveria ser o positivimo jurídico. Dessa forma, interpretar o direito, para o doutrinador, consistiria em descrever o que se pudesse extrair da norma jurídica. E, para o julgador, consistiria em conhecer o que a norma e a doutrina lhe pudessem oferecer, e a partir daí construir uma decisão. ${ }^{3}$

Apesar disso, ainda se reconhecia liberdade criadora à atividade jurisdicional, o que ocorria nas situações onde a letra da lei fosse insuficiente para a solução do caso concreto. Não por outra razão, Kelsen dizia que a atividade de interpretação do juiz era autêntica, ao passo que a atividade de interpretação da doutrina era inautêntica. A interpretação judicial seria um ato de conhecimento, mas incorporaria, também, um ato de vontade. ${ }^{4}$

MACHADO NETO, A. L. Teoria da ciência jurídica. São Paulo: Saraiva, 1975. p. 120.

3 A. L. Machado Neto pontua que Kelsen foi quem mais contribuiu para uma colocação autônoma do problema epistemológico do direito. MACHADO NETO, A. L. Teoria da ciência jurídica. São Paulo: Saraiva, 1975. p. 136.

4 "Justamente por isso, a obtenção da norma individual no processo de aplicação da lei é, na medida em que nesse processo seja preenchida a moldura da norma geral, uma função voluntária.” KELSEN, Hans. Teoria pura do direito. São Paulo: M. Fontes, 2003. p. 393.
Logo, a interpretação judicial reuniria categorias alheias ao estritamente jurídico, porém necessárias para que fosse operada uma escolha e, ao final, uma decisão. Vejam-se as palavras de Kelsen nesse sentido:

Na medida em que, na aplicação da lei, para além da necessária fixação da moldura dentro da qual se tem de manter $o$ ato a pôr, possa ter ainda lugar uma atividade cognoscitiva do órgão aplicador do Direito, não se tratará de um conhecimento do Direito positivo, mas de outras normas que, aqui, no processo da criação jurídica, podem ter a sua incidência: normas de Moral, normas de Justiça, juízos de valor sociais que costumamos designar por expressões correntes como bem comum, interesse do Estado, progresso, etc. ${ }^{5}$

No que diz respeito à atividade interpretativa judicial, Kelsen foi até este ponto, nela reconhecendo a existência de vontade. Reconheceu, inclusive, que a interpretação autêntica poderia produzir norma para além das possibilidades reveladas pela interpretação cognoscitiva, contida na moldura. ${ }^{6}$ Não se ocupou, contudo, em construir uma teoria compreensiva dos desdobramentos decorrentes daquela atividade criadora decorrente da interepretação. Isso veio a ocorrer posteriormente, com base nas reflexões trazidas pelas teorias hermenêuticas e da argumentação.?

KELSEN, Hans. Teoria pura do direito. São Paulo: M. Fontes, 2003. p. 393.

6 KELSEN, Hans. Teoria pura do direito. São Paulo: M. Fontes, 2003. p. 394.

7 A impossibilidade de definição apriorística das regras jurídicas consistiria no que Herbert Hart definiu como enunciados de textura aberta. A definição de Hart para a textura aberta do direito é a seguinte: "A textura aberta do direito significa que há, na verdade, áreas de conduta em que muitas coisas devem ser deixadas para serem desenvolvidas pelos tribunais ou pelos funcionários, os quais determinam o equilíbrio à luz das circunstâncias, entre interesses conflituantes que variam em peso, de caso para caso." HART, $\mathrm{H}$. L. A. O conceito de direito. 5. ed. Lisboa: Fundação Calouste Gulbenkian, 2007. p. 148. Exemplos dessas expressões seriam liberdade, igualdade, dignidade humana, direitos humanos, interesse público, segurança jurídica, dentre outros. Paralelamente a isso, esses enunciados normativos continuavam a abrigar princípios, mas esses princípios não seriam mais apenas diretrizes de interpretação, posicionados num patamar contingente em relação às regras. Passam a ser, sim, normas jurídicas, posicionados no mesmo patamar normativo das regras, obrigando os operadores do direito em sua observância e realização. Daniel Sarmento observa que "o reconhecimento da força normativa dos princípios jurídicos e a valorização de sua importância no processo de aplicação do Direito" é um dos traços marcantes do constitucionalismo contemporâneo. SARMENTO, Daniel. O neoconstitucionalismo no Brasil: riscos e possibilidades. In: (Coord.). Filosofia e teoria constitucional contemporânea. Rio de Janeiro: Lúmen Júris, 2009. p. 113. 
Porém, não sem problemas a possibilidade de uma atitude judicial criadora era concebida à época de Kelsen. A atividade jurisdicional destinava-se também a dar conta da interpretação constitucional a qual, na visão de Kelsen, seria mais bem exercida pelo Tribunal Constitucional alemão. ${ }^{8}$ Em sentido diverso, porém, Carl Schmitt entendia que tal tarefa seria legitimamente desempenhada apenas pelo Chefe do Poder Executivo, a quem seria reservada a guarda da Constituição (esta entendida como decisão sobre a forma de organização política da comunidade). ${ }^{9}$ Schmitt sustentava sua posição na tese de que o Chefe do Poder Executivo seria detentor de um poder neutro e intermediário, excepcional, independente dos demais e legítimo porque chancelado pelo povo. ${ }^{10} \mathrm{O}$ autor desconfiava do Parlamento alemão, o qual via como fragmentado e desprendido de seu compromisso com a defesa de uma igualdade substancial entre os cidadãos, e não meramente formal (ou, na perspectiva do autor, liberal). As circunstâncias históricas em que Schmitt construiu sua tese fizeram-no concluir que, se a Constituição alemã estava em uma situação crítica, precisava de um guardião, e este deveria ser o Presidente do Reich alemão o qual concentrava, ele sim, a vontade da maioria popular. ${ }^{11}$

KELSEN, Hans. ¿Quién debe ser el defensor de la Constitución? Madrid: Tecnos, 1995.

9 Cf. SCHMITT, Carl. La defensa de la Constitución. 2. ed. Madrid: Tecnos, 1998.

10 A teoria do pouvoir neutre, intermédiaire et régulateur é atribuída a Benjamin Constant, e foi desenvolvida para fazer frente ao bonapartismo e à Constituição monarquista. Schmitt explica que tal teoria pertence ao conjunto de teorias constitucionais do Estado cívico de Direito, e que a ela se refere "o catálogo típico de prerrogativas e atribuições do chefe de Estado (Monarca ou Presidente do Estado), imaginadas todas elas como elementos e possibilidades de intervenção de semelhante pouvoir neutre: inviolabilidade, ou, pelo menos, posição privilegiada do Chefe de Estado, referendo e promulgação de leis, prerrogativa de indulto, nomeação de Ministros e funcionários, dissolução da Câmara eleita pelo voto popular." Schmitt reúne uma série de comentários elogiosos de balizada doutrina acerca da teoria benjaminiana, dentre os quais citamos a de Lorenz von Stein, para quem o poder neutro "representa em absoluto a forma clássica do verdadeiro constitucionalismo". Cf. SCHMITT, Carl. La defensa de la Constitución. 2. ed. Madrid: Tecnos, 1998. p. 214-216.

$11 \mathrm{O}$ autor atenta que, quanto as instituições previstas na Constituição não são capazes de realizar uma unidade política homogênea, é necessário que se recorra a outros pontos do sistema social e político. Afinal, segundo Schmitt, no então vigente estado de coisas o Parlamento alemão já não consubstanciava o núcleo único onde se encontrava a
Schmitt, de fato, não poderia conceber a atividade da jurisdição como atividade política. Segundo o autor, o político está latente em todos os sujeitos, é verdade, irrompendo numa situação de conflito, quando então o sujeito exercerá a política para decidir aquele conflito. $A$ política, por outro lado, é uma atividade de competência do Governo e do Parlamento. E, se em Schmitt o político é definido pela relação tensional amigo/inimigo ${ }^{12}$, aquele que divisará quem é o amigo e quem é inimigo público da nação na circunstância histórica em que falava Schmitt somente poderia ser o Chefe do Poder Executivo, competente para decidir nesse respeito. Daí que "Definido a partir da relação amigo-inimigo, o político não requer discussão, mas decisão."13

Para Schmitt, a decisão do Chefe do Reich era buscada para conferir unidade política ao sistema. ${ }^{14}$ Assim, vozes dissonantes não eram habilitadas a interferir na posição final do Chefe do Poder Executivo. A homogeneidade postulada pelo autor alemão, de fato, implicava animus de superação de uma visão liberal do pluralismo social. Embora o Estado neutro admitisse a expressão de convicções filosóficas e religiosas contrárias à política estatal, esta neutralidade poderia se dar num Estado político se reconhecesse como inimigo todo aquele que se opusesse a essa espécie de neutralidade espiritual. ${ }^{15}$

maioria da vontade popular, mas esta mesma maioria estaria em outras entidades e instituições. E remédios neutros seriam necessários justamente para fazer frente à força do Estado de partidos em coalizão. Para Schmitt, essas entidades e organizações neutras seriam encontradas dentro da própria burocracia do Reich alemão, pois a Constituição do Reich trazia uma série de "garantias constitucionais e institucionais contra a exploração parlamentar". SCHMITT, Carl. La defensa de la Constitución. 2. ed. Madrid: Tecnos, 1998. p. 167-169.

12 "A diferenciação amigo e inimigo tem o sentido de designar o grau de intensidade extrema de uma ligação ou separação, de uma associação ou dissociação; ela pode, retórica ou praticamente, subsistir, sem a necessidade do emprego simultâneo das distinções morais, estéticas, econômicas, ou outras." Por isso é que o inimigo, para fins de determinação do político, tem o sentido de um agrupamento, de um conjunto de indivíduos que se contrapõe a um conjunto semelhante, em um sentido público. SCHMITT, Carl. O conceito do político. Petrópolis: Vozes, 1992. p. 52.

13 CHUEIRI, Vera Karam de. Nas trilhas de Carl Schmitt (ou nas teias de Kafka): soberania, poder constituinte e democracia radical. In: FONSECA, Ricardo Marcelo (Org.). Repensando a teoria do estado. Belo Horizonte: Fórum, 2004. p. 358.

15 SCHMITT, Carl. La defensa de la Constitución. 2. ed. Madrid: Tecnos, 1998. p. 183. 
É possível afirmar que a igualdade material (homogeneidade) entre os sujeitos, tal qual postulada por Schmitt, não concilia um imperativo de igual respeito e consideração pela diferença, em vista, inclusive, da potencialidade de eliminação física do inimigo. Daí que o conceito de político (e, em conjunto, de política) seja mais bem elaborado quando incorpora a diferença, o dissenso, porque em correspondência com o pluralismo e o respeito aos direitos fundamentais, tal qual experimentado na contemporaneidade, após o período entre-guerras.

A proposta de Chantal Mouffe, por exemplo, mostra-se como uma tentativa nesse sentido. $\mathrm{O}$ "regresso do político", para Mouffe, começa com o resgate de categorias como comunidade, cidadania e pluralismo. Para a autora, essencialmente, o político remete à vida em sociedade e ao antagonismo decorrente do pluralismo de ideias, de concepções de bem, com respeito ao modo de vida dos demais sujeitos. Por isso, de acordo com Mouffe, "Uma filosofia política moderna deveria articular os valores políticos, os valores que podem ser realizados através da acção coletiva e da filiação comum numa associação política. A sua matéria é a ética do político, que deveria ser distinta da moral."16 $\mathrm{O}$ sentido de alteridade presente no pensamento de Mouffe leva a sua concepção de democracia à radicalidade. Daí que, em sua visão, a democracia não é uma realidade presente, mas sim um estado permanentemente a alcançar, pois não pode haver decisão final em um ambiente onde convivem diferentes concepções de bem e de justo. ${ }^{17}$

A tese de Mouffe mostra preocupações contemporâneas da teoria política, no sentido de filtrá-la com teorias democráticas que resgatem a atuação dos sujeitos em suas comunidades, com igual respeito e consideração pelos demais. ${ }^{18}$ Acreditar no engajamento dos sujeitos em sua comunidade, como capazes de exercer um papel tran-

16 MOUFFE, Chantal. O regresso do político. Lisboa: Gradiva, 1996. p. 80.

17 "Longe de ser o resultado necessário de uma evolução moral da humanidade, a democracia é algo de incerto e improvável e nunca deve ser tida como garantida." MOUFFE, Chantal. O regresso do político. Lisboa: Gradiva, 1996. p. 17.

18 Por isso é que, em outra passagem, a autora pontua que "A principal questão da política democrática, portanto, não é como eliminar o poder, mas como constituir formas de poder que sejam compatíveis com valores democráticos." MOUFFE, Chantal. Democracy, power, and the "political". In: BENHABIB, Seyla (Org.). Democracy and difference: contesting de boundaries of the political. Princeton: Princeton University Press, 1996. p. 248. formador, é o que fez Hanna Arendt conceber que "zoon politikon é a pessoa que se engaja seriamente e com responsabilidade nas questões públicas sob os auspícios das instituições públicas." ${ }^{19}$ Para Mouffe, o reconhecimento da diferença impede que se chegue a um ponto final, universal, acerca do que seja moralmente válido. Assim é que "Uma concepção moderna de cidadania deve respeitar o pluralismo e a liberdade individual; devemos resistir a qualquer tentativa de reintroduzir uma comunidade moral, de regressar a uma universitas. ${ }^{20}$ A decisão política não terá legitimidade se construída sem discussão e deliberação acerca do gerenciamento dos assuntos públicos, ou que sejam de interesse público, para conferir, nas palavras de Santiago Nino, um maior "valor epistêmico" às decisões morais ${ }^{21}$ (afinal, nas palavras de Seyla Benhabib, "Deliberação é um processo para se ser informado)."22 E é precisamente o déficit de legitimidade da atividade judicial de jurisdição constitucional que a faz ser vista com profunda desconfiança. Afinal, decisões públicas envolvem compreensões acerca de questões morais, vinculantes para os cidadãos que participam de uma comunidade que se reconheça como tal. Uma das preocupações que impulsionaram Jürgen Habermas, por exemplo, a pensar a justificação procedimental de decisões públicas foi, justamente, a legitimidade da jurisdição constitucional para discutir a validade dessas decisões.

Por se preocupar com a legitimidade das decisões judiciais que operam uma leitura de acordos morais (e Habermas acredita ser possível existirem tais acordos, ou um "conteúdo cognitivo da moral"), Habermas pensa a racionalidade de decisões que eventualmente desbordem da aplicação ordinária de acordos moralmente válidos. A

19 Cf. WALDRON, Jeremy. Arendt's constitutional politics. In: VILlA, Dana (Org.). The Cambridge Companion to Hannah Arendt. New York: Cambridge University Press, 2002. p. 202. E, também, a possibilidade de uma comunidade dar-se para si, legitimamente, uma constituição, como expressão não da limitação do poder, mas sim do seu estabelecimento, criando um novo governo. ARENDT, Hannah. On revolution. New York: Penguin Books, 2006. p. 132-145.

20 MOUFFE, Chantal. O regresso do político. Lisboa: Gradiva, 1996. p. 80.

21 Cf. SANTIAGO NINO, Carlos. La constitución de la democracia deliberativa. Barcelona: Gedisa, 1997.

22 BENHABIB, Seyla. Toward a deliberative model of democratic legitimacy. In: ___ (Org.). Democracy and difference: contesting de boundaries of the political. Princeton: Princeton University Press, 1996. p. 71. 
teoria do direito de Habermas é informada pela perspectiva da teoria do discurso, dentro de um paradigma procedimental. Essa visão procedimental de racionalidade da interpretação do direito pressupõe um espaço de deliberação onde todos os argumentos podem ser livremente apresentados e discutidos, a fim de que se assegure "idealmente que todas as razões e informações relevantes, das quais em um determinado momento se possa dispor com relação a um tema, possam se fazer ouvir sem exceção."23

O perigo de uma atitude política da jurisdição, conforme Habermas, seria o risco da atividade judicial se reduzir a uma juriprudência de valores. A jurisprudência de valores consistiria no fato da interpretação judicial do direito, em lugar de operar uma escolha entre normas válidas, operar uma escolha entre valores, através de um sopesamento dos bens abrigados por aqueles valores. Reconhecer um discurso de justificação sustentado sobre valores abre espaço para a eleição pessoal do julgador acerca de uma concepção de bem (ou o alcance de um determinado fim), sem que essa concepção de bem seja compartilhada pela comunidade de intérpretes. ${ }^{24}$ Isso

23 HABERMAS, Jürgen. Facticidad y validez: sobre el derecho y el Estado democrático de derecho en términos de teoría del discurso. 6. ed. Madrid: Trotta, 2010. p. 299.

24 Michel Rosenfeld observa que Habermas pretende imprimir à sua visão procedimental de justiça uma certa neutralidade substancial, uma certa isenção com relação à escolha das perspectivas que farão parte da deliberação acerca dos acordos morais. Contudo, Rosenfeld pontua que, bem da verdade, o paradigma procedimental é excludente de outros paradigmas, e, assim, opera escolhas substantivas. Por exemplo, exclui perspectivas metafísicas, por posicionar-se em uma perspectiva pós-metafísica. Exclui, também, perspectivas não-metafísicas que rejeitem aderência à prescrição de equidade, como é o caso de sujeitos que se considerem inerentemente superiores, recusando-se a submeter à discussão com sujeitos inferiores a sua visão de justiça. ROSENFELD, Michel. Overcoming interpretation through dialogue: a critique of Habermas's proceduralism Conception of Justice. In: _. Just interpretations: law between ethics and politics. Berkeley: University of California Press, 1998. p. 136-137. O contraponto entre Habermas e Rosenfeld parece residir na possibilidade da concepção procedimental de justiça habermasiana alcançar um acordo moral. Afinal, na visão reconstrutivista de Rosenfeld, o direito pode incorporar a pluralidade de convicções éticas igualmente relevantes em uma determinada comunidade, desde que não implique a supressão de outras convicções éticas (o que seria uma violência), e daí o autor negar a possibilidade de uma moral objetiva. De fato, a moral objetiva, na visão de Rosenfeld, estaria impossibilitada por conta do dever de alteridade, que impõe uma atitude desconstrutivista, culminante na impossibilidade de alcance da justiça. Mas, para Habermas a justiça não vem a ser, a justiça é, e é eleva o risco de serem proferidos juízos irracionais, pois argumentos finalísticos tomam o lugar de argumentos normativos. Daí que a visão procedimental de justiça, em termos de legitimidade da jurisdição constitucional, no exercício de interpretação do direito, seja expressada na posição da jurisdição constitucional não como protagonista da definição de direitos, mas sim na posição de árbitro, ou tutor de um certo procedimento de que dependa a eficácia legitimadora de um certo processo democrático de produção normativa (jurídica).

A preocupação com embeber modelos de controle (jurisdicional) de constitucionalidade com aportes democráticos é uma constante nas teorias constitucionais contemporâneas. Isso faria com que a atividade política da jurisdição constitucional ganhasse em termos de legitimidade. Pensar o controle de constitucionalidade em termos procedimentais pertimiria, inclusive, proteger o discurso das minorias frente ao discurso dominante das maiorias. O controle abstrato de constitucionalidade, revisor de leis e atos normativos em tese, poderia destinar-se a operar um controle procedimental, assegurando, apenas, as condiçõos da gênese democrática dos atos políticos. Esse controle sobre o procedimento se ocuparia em

[...] ouvir as vozes desviantes e das quais se possa fazer um uso concreto e efetivo dos direitos de participação, em princípio formalmente iguais, e concluindo com a representação equilibrada de todos os grupos, constelações de interesses e orientações valorativas relevantes em cada caso, no plano dos organismos parlamentares e no espectro de temas, razões e problemas, dos valores e interesses, que podem integrar as deliberações parlamentares e ser levados em conta na fundamentação das normas que se discutem e aprovam. ${ }^{25}$

Nota-se, a partir desses debates, que o atuar político é comum a todos aqueles que se envolvam na discussão de assuntos de interesse público, deles participando com poder de decisão. Com Kelsen, pode-se dizer que, ainda que se adote a definição de política como "decisão" orientada à solução de interesses, então "em toda decisão judicial está presente, em maior ou menor medida, um

procedimental. ROSENFELD, Michel. Just interpretations? Law, violence, and the paradox of justice. In: __ Just interpretations: law between ethics and politics. Berkeley: University of California Press, 1998. p. 72.

25 ROSENFELD, Michel. Just interpretations? Law, violence, and the paradox of justice. In:___ Just interpretations: law between ethics and politics. Berkeley: University of California Press, 1998. p. 339. 
elemento de decisão, um elemento de exercício de poder." Por isso, no entender do autor, "Entre o caráter político da legislação e o da jurisdição há apenas uma diferença quantitativa, e não qualitativa." ${ }^{26}$

A fiscalização jurisdicional de constitucionalidade envolve atividade política. Esse traço da jurisdição assume especial relevância quando se trata do controle abstrato de constitucionalidade, hipótese em que há a cassação do ato político sob discussão. Nesse respeito, mencione-se que a Constituição de 88 autoriza que toda e qualquer questão (política, inclusive) seja legitimamente levada a conhecimento da jurisdição (art. 5..$^{\circ}$ XXXV). Sob o egime anterior, Paulino Jacques já afirmava não ser possível apartar a análise de questões políticas da jurisdição, sob pena de inutilidade desta. ${ }^{27}$ Para referido autor, "a 'questão política' não é apenas questão de conveniência, oportunidade e acerto; mas, também, de interesse nacional com repercussão em interesses individuais." 28

A desconfiança sobre o controle jurisdicional de constitucionalidade repousa, sem dúvida, sobre a parcela política da atividade jurisdicional e sua dificuldade democrática. A partir das premissas teóricas aqui trazidas, tem-se que o político é, pois, desde uma perspectiva intersubjetiva, pluralismo, inclusão, reconhecimento do indivíduo com igualdade perante a comunidade que integra e, também, auto-governo coletivo. É, também, desde uma perspectiva individual, atuação política na comunidade. Juízes exercem atividade política não apenas desde uma perspectiva individual, no sentido de atuação e militância em favor de uma causa. Juízes são agentes políticos integrados em um sistema de realização de fins - traçados no direito - e o fazem a partir do exercício da parcela de poder público que lhes é atribuída por esse mesmo sistema político-jurídico. Exercem, também, atividade política desde uma perspectiva coletiva, pois suas decisões interferem na condução de assuntos da ordem governativa e, mais do que isso, criam direito. Essas são razões que por si sós justificam o interesse em eventuais experiências de expansão da atividade judicante além da brasileira. No próximo tópico, serão apresentadas altera-

26 KELSEN, Hans. ¿Quién debe ser el defensor de la Constitución? Madrid: Tecnos, 1995. p. 18-19.

27 JACQUES, Paulino. Curso de direito constitucional. 9. ed. Rio de Janeiro: Forense, 1983. p. 329.

28 JACQUES, Paulino. Curso de direito constitucional. 9. ed. Rio de Janeiro: Forense, 1983. p. 329. ções recentes em três modelos jurídicos estrangeiros, nos quais é visualizada tal expansão.

\section{Alterações recentes no controle de constitu- cionalidade em modelos estrangeiros}

\subsection{0 modelo inglês}

Um dos pressupostos para a deflagração da fiscalização de constitucionalidade é a existência de uma constituição escrita. ${ }^{29}$ A constituição escrita é parâmetro frente ao qual a legitimidade de leis e atos normativos é aferida nos países que admitem tal controle. Bem por isso, nos sistemas em que vigentes constituições costumeiras, ou não-escritas, não se experimenta o controle de constitucionalidade de leis e atos normativos. É o caso, por exemplo, da Inglaterra, onde um plexo de leis (em sentido amplo $)^{30}$ constitui o que se reconhece como uma Constituição. Assim é que, na Inglaterra, desde a Revolução Gloriosa de 1688, e seja para assegurar a supremacia da lei, seja para assegurar a supremacia da common law, ao juiz tem sido reservado o papel de apenas interpretar o direito sem, contudo, cassar as opções legislativas. Daí a histórica inexistência, no modelo inglês, de uma Suprema Corte, responsável pelo controle de constitucionalidade de leis e atos normativos.

No ano de 2005, porém, esse cenário apresentou mudanças significativas. O Constitutional Reform Act 2005, votado pelo Parlamento, promoveu alterações no sistema constitucional inglês. Se antes o papel de última instância de apelação no desenho jurisdicional da Grã-Bretanha era cumprido pelo Appellate Committee of the House of Lords, agora esta tarefa foi transferida para a então criada UK Supreme Court, inslatada em novembro de 2009. O Act, como é chamado o Constitutional Reform Act de 2005, estabelece que a Suprema Corte será composta de 12 juízes. A BBC, agência pública de notícias bri-

(9ASTOS, Celso Ribeiro. Curso de direito constitucional. 22. ed. São Paulo: Saraiva, 2001. p. 322.

30 Como lei em sentido amplo, aqui, refere-se à lei em sentido material, cf. CLÈVE, Clèmerson Merlin. Atividade legislativa do Poder Executivo. 3. ed. São Paulo: Revista dos Tribunais, 2011. Inclui-se, aqui, também, portanto, o "o direito casuístico ou jurisprudencial (case law), o costume, mormente o de natureza parlamentar (Parliamentary custom)". A existência de textos escritos esparsos, componentes da Constituição inglesa, faz com que Paulo Bonavides a reconheça como apenas parcialmente costumeira. BONAVIDES, Paulo. Curso de direito constitucional. 21. ed. São Paulo: Malheiros, 2007. p. 84. 
tânica, informa que “os 12 juízes serão os 'árbitros finais' entre os cidadãos e o Estado, o [check and balance] final de que a lei é aplicada corretamente e com justiça." ${ }^{31}$ Os 12 primeiros juízes da Corte são os mesmos Law Lords do Appellate Committee. Após, a nomeação de novos membros será operada por uma comissão de seleção inaugurada a partir dos membros atuais, em conjunto com o Primeiro Ministro e a Rainha.

A competência da novel Suprema Corte compreende: todos os casos civis do Reino Unido e todos os casos criminais, exceto aqueles sob jurisdição da Escócia; alguns casos da União Europeia e todos envolvendo questões de competência entre País de Gales, Escócia e Irlanda do Norte. Um ponto relevante é que a Suprema Corte, assim como o antigo Appelate Commitee da House of Lords, julga apenas causas de relevância e transcendência públicas. Ou seja, há um julgamento em certa medida político dos membros da própria Corte acerca da admissibilidade dos casos a serem examinados.

Diante de tais inovações, especula-se que a Suprema Corte britânica aproxime-se do papel ativo desempenhado pela Suprema Corte norte-americana, exercendo a judicial review. ${ }^{32}$ Lembre-se, porém, de que a Suprema Corte do Reino Unido não tem competência para cassar atos legislativos, limitando-se, apenas, à interpretação quanto à sua aplicação. Apesar disso, não parece ser o caso, porém, e como pontuou Lord Phillips, de ter havido meramente mais uma mudança de "forma do que de conteúdo." 33 Afinal, além do Appelate Commitee estar próximo do Parlamento, as sessões de julgamento, embora gravadas, eram entregues no âmbito parlamentar. Já a Supreme Court tem prédio próprio, é separada fisicamente e institucionalmente do Parlamento, o que é algo significativo. Também, toda as audiências da Suprema Corte são abertas ao público e, pela primeira vez na história do direito britânico, câmeras de televisão estarão permanentemente na Corte. Conclui-se, portanto que, no mínimo,

31 CASCIANI, Dominic. QઐA: UK Supreme Court. Sept. 2009. Disponível em: <http://news.bbc.co.uk/2/hi/uk news/8283967.stm>. Acesso em: 10 abr. 2010.

32 Cf. ROWE, Jenny. The New UK Supreme Court. Jan. 2010. Disponível em: <http://www.metrocorpcounsel.com/ pdf/2010/January/27.pdf >. Acesso em: 10 abr. 2010.

33 CASCIANI, Dominic. Q\&A: UK Supreme Court. Sept. 2009. Disponível em: <http://news.bbc.co.uk/2/hi/uk news/8283967.stm>. Acesso em: 10 abr. 2010. a Suprema Corte do Reino Unido tem um papel público deveras maior que o do Appelate Commitee.

\subsection{0 modelo belga}

A “Lei Especial de Reformas Constitucionais”, de 8 de agosto de 1980, previu a criação de uma "Corte de Arbitragem", no art. 170 da Constituição belga (hoje art. 142). A Lei de 28 de junho de 1983 estabeleceu as atribuições e o funcionamento dessa Corte. Até 1989, a competência da Corte compreendia resolução de litígios sobre repartição de competências entre os diversos órgãos do Estado. ${ }^{34}$ A partir de 1989, a competência foi ampliada para casos envolventes de direitos fundamentais, restritos, no entanto, a violações a três artigos da Constituição belga: ao princípio da igualdade e da não discriminação (arts. 10 e 11) e à liberdade de ensino (art. 24 da Constituição), todos contidos no Título II da Lei Fundamental.

Em 9 de março de 2003, lei especial estendeu formalmente o campo de competência da Corte de Arbitragem para a proteção de todos os direitos e liberdades fundamentais enunciados no Título II da Constituição da Bélgica (art. 8 a 32). Alguns autores entendem que essa ampliação de competência de controle nada mais fez do que consagrar um trabalho que já vinha sendo feito pela Corte de Arbitragem, a partir da interpretação dos dispositivos cujo controle já era autorizado por lei. ${ }^{35}$

A jurisprudência belga já vinha mitigando a denominação da Cour d'Arbitrage como Cour à compétence restreinte, por conta da crescente atividade jurisprudencial, especialmente em matéria de direitos fundamentais. Veja-se o comentário de Louis Favoreu, anterior à ampliação do parâmetro de fiscalização, a esse respeito:

Sua atividade [da Corte de Arbitragem] aumentou visivelmente após a extensão da competência da Corte à proteção de alguns direitos fundamentais. De julho de 1989 até o fim de 1992, ela proferiu 101 acórdãos sobre disposições le-

34 E esta teria sido a razão de ser da criação da Corte. Para Marie-Françoise Rigaux e Bernadette Renauld, “ [...] é certo que a Corte de Arbitragem nasceu na Bélgica pela necessidade de garantir a existência do Estado, em cujo seio era necessário garantir o respeito ao equilíbrio de competências entre cada um dos seus entes." (RIGAUX, Marie-Françoise; RENAULD, Bernadette. La cour constitutionnelle. Bruxelles: Bruylant, 2009. p. 25. Tradução livre.) No mesmo sentido, informa FAVOREU, Louis. As cortes constitucionais. São Paulo: Landy, 2004. p. 120.

35 É o que informam RIGAUX, Marie-Françoise; RENAULD, Bernadette. La cour constitutionnelle. Bruxelles: Bruylant, 2009. p. 65. 
gislativas federais e 18 decisões de invalidação. Estas foram em número de 25 em 1993-1994. Se acrescentarmos a elas as 28 invalidações decretadas antes de 1989, chegaremos a um total de 71 casos, o que é muito e mostra a efetividade do controle feito pela Corte de Arbitragem. ${ }^{36}$

Some-se a essa atuação a ampliação do parâmetro de fiscalização de constitucionalidade, e a Corte de Arbitragem foi reconhecida como verdadeira Corte constitucional:

O alargamento do parâmetro de constitucionalidade e dos instrumentos de acesso, juntamente com a juridicização do processo constitucional, leva a que se considere a hoje já referida Corte de Arbitragem como uma verdadeira Corte Constitucional, como, de fato, a própria mudança de nome está a demonstrar. ${ }^{37}$

A revisão constitucional de 7 de maio de 2007 modificou formalmente o nome da Corte de Arbitragem para "Corte Constitucional", a qual exerce o controle concreto e abstrato de constitucionalidade. ${ }^{38}$

Todas essas modificações parecem poder justificar a assertiva de Favoreu no sentido de que "A justiça constitucional cumpre, doravante, uma função essencial no sistema político e jurídico belga." ${ }^{39}$

\subsection{0 modelo francês}

O modelo francês de controle de constitucionalidade é tradicionalmente conhecido como aquele em que operado controle político, e não jurisdicional, pelo Conseil Constitutionnel ${ }^{40}$. Desde o período posterior à revolução de 1789, o controle de constitucionalidade de leis na França sempre foi confiado a órgão de natureza não judiciária ${ }^{41}$. Dentre as razões para tal mencionam-se

36 FAVOREU, Louis. As cortes constitucionais. São Paulo: Landy, 2004. p. 122.

37 PEGORARO, Lucio. Giustizia costituzionale comparata. Torino: Giappichelli, 2007. p. 86-87.

38 RIGAUX, Marie-Françoise; RENAULD, Bernadette. La cour constitutionnelle. Bruxelles: Bruylant, 2009. p. 22-29.

39 FAVOREU, Louis. As cortes constitucionais. São Paulo: Landy, 2004. p. 122.

40 No ponto, Mauro Cappelletti observa que "o 'parecer vinculatório' do Conseil Constitutionnel é, certamente, um parecer jurídico (de constitucionalidade) e não uma mera avaliação de oportunidade política, sem com isto assumir, porém, o caráter de um verdadeiro julgamento em sentido jurisdicional." CAPPELLETTI, Mauro. O controle judicial de constitucionalidade das leis no direito comparado. 2. ed. Porto Alegre: S. A. Fabris, 1999. p. 29, nota 17. a desconfiança sobre os juízes por conta das experiências de abusos e arbitrariedades tidas com os Parlementaires (juízes das precedentes Cortes Superiores), e também a rígida formulação da doutrina da separação dos poderes na França, impedindo qualquer interferência dos juízes na esfera do poder legislativo, este visto como via de manifestação da soberania popular. ${ }^{42}$

Ao Conseil Constitutionnel, constituído sob a Constituição francesa de 1958, existente até hoje, sempre foi reservado papel consultivo acerca da constitucionalidade de leis, às vezes obrigatoriamente (no caso de leis orgânicas), às vezes facultativamente ${ }^{43}$. Esse papel consultivo, por natureza, expressa parecer prévio acerca da constitucionalidade da lei, ou seja, é anterior à sua promulgação. Bem por isso, observa Cappelletti não se trata de um verdadeiro "controle" mas, antes, de "um ato (e precisamente um parecer vinculatório) que vem a se inserir no próprio processo de formação da lei - e deste processo assume, portanto, a mesma natureza." ${ }^{44}$ Daí afirmar-se que " Após a promulgação, não haverá lugar, portanto, para a manifestação de qualquer mecanismo de aferição da legitimidade constitucional da lei." ${ }^{45}$

O tradicional cenário da fiscalização de constitucionalidade meramente preventiva, vigente no modelo francês, contudo, sofreu alterações significativas com a reforma constitucional de 2008.

Em 23 de julho de 2008, foi promulgada lei constitucional que inseriu na Constituição francesa de 1958 o artigo 61-1, modificando, também, a redação do art. 62, ao criar procedimento de controle sucessivo de constitucionalidade de leis por via de exceção. Trata-se de controle exercido pelo Conselho Constitucional, e suscitado pela Corte de Cassação ou pelo Conselho de Estado a partir

S. A. Fabris, 1999. p. 95. Para uma revisão da questão do controle de constitucionalidade na França, desde 1814, com o Sénat, sob a Constituição de 1799, até os dias de hoje, com a criação do Conseil Constitutionnel, sob a Constituição de 1958, ver FAVOREU, Louis et al. Droit constitutionnel. 12. ed. Paris: Dalloz, 2009. p. 287-377.

42 CAPPELLETTI, Mauro. O controle judicial de constitucionalidade das leis no direito comparado. 2. ed. Porto Alegre: S. A. Fabris, 1999. p. 97.

43 HAMON, Francis; TROPER, Michel. Droit constitutionnel. 30. ed. Paris: L.G.D.J., 2007. p. 833-846.

44 HAMON, Francis; TROPER, Michel. Droit constitutionnel. 30. ed. Paris: L.G.D.J., 2007. p. 29.

45 Cf. CLĖVE, Clèmerson Merlin. A fiscalização abstrata da constitucionalidade no direito brasileiro. 2. ed. São Paulo: Revista dos Tribunais, 2000. p. 56. 
de questão de constitucionalidade levantada em qualquer processo judicial, em todas as instâncias de jurisdição.

Conforme as alterações trazidas pela reforma de 2008, o ato legislativo impugnado deve atentar contra os direitos e liberdades garantidos na Constituição. Nesse ponto, é de se observar que o campo de incidência do novel controle de constitucionalidade é deveras vasto, pois se tratam aqui de "direitos e liberdade" inscritos no "bloco de constitucionalidade", compreendendo não só o texto da Constituição francesa mas, igualmente, os textos citados em seu Preâmbulo. ${ }^{46}$ Uma limitação proposta no projeto de revisão é que leis que sejam posteriores a 1958 e que ainda não tenham passado pelo crivo do Conselho não estariam sujeitas a tal modalidade de controle. ${ }^{47} \mathrm{~A}$ Corte tem poderes para que a decisão de inconstitucionalidade surta efeitos no mundo jurídico a partir da publicação da respectiva decisão, ou de outro momento que venha a ser por ela fixado.

O procedimento incidental aplicável para suscitar a questão de inconstitucionalidade foi regulamentado pela Lei Orgânica n. ${ }^{\circ}$ 2009-1523 de 10 de dezembro de 2009, e chamado "questão prioritária de constitucionalidade" (QPC). A qualificação do procedimento como "prioritário" por referida Lei seria justificada por duas razões: a primeira, e de um ponto de vista substantivo, porque a questão ali envolvida assume esse caráter ao conferir "ao jurisdicionado o direito, até então inexistente, de demandar pela ab-rogação da lei", sendo obrigatória uma resposta do juízo competente à questão suscitada. $\mathrm{E}$ a segunda, de um ponto de vista objetivo, porque, quando a lei qualifica a questão como prioritária, deixa claro que deve ser apreciada antes de todas as outras para a solução do litígio. ${ }^{48}$

Surge, pois na França, algo próximo de um controle difuso (e sucessivo) de constitucionalidade das leis, porque a questão de constitucionalidade é suscitada como questão prejudicial de fundo em um processo subjetivo. Lembre-se, porém, que, no caso da QPC, o juiz da causa

46 FAVOREU, Louis et al. Droit constitutionnel. 12. ed. Paris: Dalloz, 2009. p. 335.

47 FAVOREU, Louis et al. Droit constitutionnel. 12. ed. Paris: Dalloz, 2009. p. 336.

48 Cf. GUILLAUME, Marc. La question prioritaire de constitutionnalité. Disponível em: <http://www.conseil-constitutionnel.fr/conseil-constitutionnel/francais/la-question-prioritaire-de-constitutionnalite/decouvrir-la-qpc/ decouvrir-la-question-prioritaire-de-constitutionnalite-qpc.47106.html>. Acesso em: 15 nov. 2010. não está autorizado a, ele mesmo, questionar a constitucionalidade da lei em tela, sendo tal iniciativa reservada às partes do processo. ${ }^{49}$

Os reflexos políticos da ampliação de competências do Conselho Constitucional são visíveis. Tais efeitos não podem ser apartados de um agir político do Conselho em alguma medida, ainda que no sentido de interferência decisiva na condução dos assuntos públicos de uma comunidade. Nesse sentido, a opinião de Louis Favoreu, ainda antes das reformas que culminaram na criação da questão prioritária de constitucionalidade:

Os efeitos da intervenção do Conselho Constitucional sobre a vida política são diversos, mas obedecem à mesma lógica.

Em primeiro lugar, o controle exercido pelo Conselho Constitucional contribuiu, de maneira decisiva, para pacificar a vida política. Isso aconteceu em diversas ocasiões. A paixão sempre diminuía depois que a decisão do Conselho Constitucional era proferida. Se o controle das leis preenche essa função é porque a oposição tem à sua disposição um meio de assegurar que a maioria não ultrapasse os limites fixados pela Constituição.

Isso explica que a existência e a ação do Conselho Constitucional tenham facilitado e permitido a alternância em 1981-1982. De fato, através da autolimitação da maioria pelo temos de ser censurada, o juiz constitucional assegurou a regulação do processo de mudança, canalizando as reformas, isto é, indicando quais estavam abertas à maioria para criar novas normas jurídicas e quais vias estavam fechadas para elas por não dispor de um consenso suficiente..$^{50}$

\section{Conclusões}

As razões que tenham conduzido às modificações institucionais mencionadas ligam-se a peculiaridades dos seus respectivos sistemas constitucionais. Por ora, deixa-se de investigar tais razões aqui. Fato é, no entanto, que há um elemento central comum em tais mudanças: a jurisdição tem assumido uma posição de centralidade nos ordenamentos jurídicos contemporâneos, exercendo papel político consistente em uma intervenção institucional reforçada e decisiva nos assuntos públicos. Afinal, "Tudo o que é de interesse público é político de certo modo, e

49AVOREU, Louis et al. Droit constitutionnel. 12. ed. Paris: Dalloz, 2009. p. 336.

50 FAVOREU, Louis. As cortes constitucionais. São Paulo: Landy, 2004. p. 102. 
nada do que essencialmente interessa ao Estado pode ser seriamente despolitizado." ${ }^{11}$

No Reino Unido, a criação da nova Suprema Corte, como mencionado, manteve as atribuições originalmente conferidas aos Lordes do precedente Appellate Commitee no que pertine à atividade jurisdicional. Apesar disso, é de se considerar o tão-só fato da instituição de um órgão ao menos formalmente apartado do Parlamento (no caso, uma Suprema Corte), sugerindo um sentido de independência. Além disso, a publicidade das discussões travadas em torno de questões de relevância pública é um passo rumo não só à responsabilidade política dos julgamentos da novel Suprema Corte, como, também, rumo à chamada da população para dentro dos debates acerca de temas do seu interesse, ainda que, num primeiro momento, essa chamada limite a sua participação efetiva sobre as decisões.

Na Bélgica, a ampliação do parâmetro de fiscalização de constitucionalidade, compreendido inicialmente em um campo restrito de artigos da Constituição, parece expressar maior confiança no trabalho da antes Corte de Arbitragem. Tanto é assim que a Corte, como mencionado, agora se chama formalmente Corte Constitucional. A atividade de interpretação constitucional com caráter de definitividade envolve juízo político acerca de questões públicas, especialmente quando este juízo envolver a proteção de direitos fundamentais, como é o caso da agora ampliada competência da Corte. Parece haver, também aqui, mais um caso de atribuição, para uma Corte Constitucional, de competência para exercer o papel político de implementação de direitos.

Finalmente, o caso da França parece ser o mais expressivo. Se historicamente o sistema institucional francês incorporava uma evidente desconfiança com relação ao papel da jurisdição na construção do direito, agora parece abrir espaço para um atuar político dessa mesma jurisdição. A sobrevinda de um mecanismo de fiscalização de constitucionalidade, sucessivo embora difuso, inaugura o que se pode reconhecer como uma participação marcante da jurisdição (do Conselho Constitucional) no trato de matérias de interesse nacional, embora com repercussão restrita a interesses individuais em um processo. Trata-se de um papel político inaugural no modelo de controle de constitucionalidade francês, porque autoriza a cassação da escolha política contrária à Constituição.

51 SCHMITT, Carl. La defensa de la Constitución. Trad. Manuel Sanchez Sarto. 2. ed. Madrid: Tecnos, 1998. p. 182.
Essas conclusões nem de longe são definitivas acerca do que tais mudanças institucionais representam seja para cada ordenamento jurídico em que se inserem, seja para a filosofia constitucional como um todo. De qualquer forma, expressam, certamente, que o político não está restrito ao atuar do Chefe do Executivo, das maiorias parlamentares, ou das comunidades organizadas no exercício deliberativo de suas escolhas. O político encontra-se, também, no atuar jurisdicional, quando este tem seu campo ampliado para uma participação cada vez mais proeminente em um desenho institucional. Os limites e possibilidades dessa atuação merecem investigação própria, o que se deixa para outra oportunidade.

\section{Referências}

ARENDT, Hannah. On revolution. New York: Penguin Books, 2006.

BASTOS, Celso Ribeiro. Curso de direito constitucional. 22. ed. São Paulo: Saraiva, 2001.

BENHABIB, Seyla. Toward a deliberative model of democratic legitimacy. In: (Org.). Democracy and difference. contesting de boundaries of the political. Princeton: Princeton University Press, 1996.

BONAVIDES, Paulo. Curso de direito constitucional. 21. ed. São Paulo: Malheiros, 2007.

CAPPELLETTI, Mauro. O controle judicial de constitucionalidade das leis no direito comparado. 2. ed. Porto Alegre: S. A. Fabris, 1999.

CASCIANI, Dominic. Q\&AA: UK Supreme Court. Sept. 2009. Disponível em: <http://news.bbc.co.uk/2/hi/uk_ news/8283967.stm>. Acesso em: 10 abr. 2010.

CLÈVE, Clèmerson Merlin. A fiscalização abstrata da constitucionalidade no direito brasileiro. 2. ed. São Paulo: Revista dos Tribunais, 2000.

CLÈVE, Clèmerson Merlin. Atividade legislativa do Poder Executivo. 3. ed. São Paulo: Revista dos Tribunais, 2011.

CHUEIRI, Vera Karam de. Nas trilhas de Carl Schmitt (ou nas teias de Kafka): soberania, poder constituinte e democracia radical. In: FONSECA, Ricardo Marcelo (Org.). Repensando a teoria do Estado. Belo Horizonte: Fórum, 2004.

FAVOREU, Louis. As cortes constitucionais. São Paulo: Landy, 2004.

FAVOREU, Louis et al. Droit constitutionnel. 12. ed. Paris: Dalloz, 2009. 
GUILLAUME, Marc. La question prioritaire de constitutionnalité. Disponível em: <http://www.conseil-constitutionnel.fr/conseil-constitutionnel/francais/la-question-prioritaire-de-constitutionnalite/decouvrir-la-qpc/ decouvrir-la-question-prioritaire-de-constitutionnalite-qpc.47106.html>. Acesso em: 15 nov. 2010.

HABERMAS, Jürgen. Facticidad y validez: sobre el derecho y el Estado democrático de derecho en términos de teoría del discurso. 6. ed. Madrid: Trotta, 2010.

HAMON, Francis; TROPER, Michel. Droit constitutionnel. 30. ed. Paris: L.G.D.J., 2007.

HART, H. L. A. O conceito de direito. 5. ed. Lisboa: Fundação Calouste Gulbenkian, 2007.

JACQUES, Paulino. Curso de direito constitucional. 9. ed. Rio de Janeiro: Forense, 1983.

KELSEN, Hans. ¿Quién debe ser el defensor de la Constitución? Madrid: Tecnos, 1995.

KELSEN, Hans. Teoria pura do direito. São Paulo: M. Fontes, 2003.

MACHADO NETO, A. L. Teoria da ciência jurídica. São Paulo: Saraiva, 1975.

MOUFFE, Chantal. O regresso do político. Lisboa: Gradiva, 1996.

MOUFFE, Chantal. Democracy, power, and the "political". In: BENHABIB, Seyla (Org.). Democracy and difference: contesting de boundaries of the political. Princeton: Princeton University Press, 1996.
SANTIAGO NINO, Carlos. La constitución de la democracia deliberativa. Barcelona: Gedisa, 1997.

PEGORARO, Lucio. Giustizia costituzionale comparata. Torino: Giappichelli, 2007.

RIGAUX, Marie-Françoise; RENAULD, Bernadette. La cour constitutionnelle. Bruxelles: Bruylant, 2009.

ROSENFELD, Michel. Overcoming interpretation through dialogue: a critique of Habermas's proceduralism Conception of Justice. In: . Just interpretations: law between ethics and politics. Berkeley: University of California Press, 1998.

ROSENFELD, Michel. Just interpretations? Law, violence, and the Paradox of Justice. In: Just interpretations: law between ethics and politics. Berkeley: University of California Press, 1998.

ROWE, Jenny. The new UK Supreme Court. Jan. 2010. Disponível em: <http://www.metrocorpcounsel.com/ pdf/2010/January/27.pdf>. Acesso em: 10 abr. 2010.

SARMENTO, Daniel. O neoconstitucionalismo no Brasil: riscos e possibilidades. In: (Coord.). Filosofia e teoria constitucional contemporânea. Rio de Janeiro: Lúmen Júris, 2009.

SCHMITT, Carl. O conceito do político. Petrópolis: Vozes, 1992.

SCHMITT, Carl. La defensa de la Constitución. 2. ed. Madrid: Tecnos, 1998.

WALDRON, Jeremy. Arendt's constitutional politics. In: VILLA, Dana (Org.). The Cambridge Companion to Hannah Arendt. New York: Cambridge University Press, 2002. 